\title{
Selectividad étnica en el discurso migratorio de Vox: entre el pragmatismo y el esencialismo
}

\author{
Zakariae Cheddadi El Haddad
}

Universidad del País Vasco (UPV/EHU). Departamento de Sociología y Trabajo Social zakariae.cheddadi@ehu.eus

\section{José Manuel León Ranero}

Universidad del País Vasco (UPV/EHU). Departamento de Ciencia Política y de la

Administración

josemanuel.leon@ehu.eus

\section{Resumen}

La irrupción política del partido de derecha radical Vox en el sistema político español ha abierto nuevos espacios para la investigación académica, y uno de los más pertinentes es el estudio de su discurso migratorio. Partiendo de la hipótesis central de la existencia de un discurso diferenciado sobre la inmigración en función del origen étnico, el trabajo tiene como objetivo determinar su relevancia, orientación y argumentación. Para la realización de esta investigación, se ha optado por una metodología cualitativa a través de la aplicación del análisis de contenido y del método de la cadena causal a una muestra de fuentes documentales y audiovisuales. Los resultados de este estudio revelan que Vox utiliza un discurso de diferenciación étnica bimodal de naturaleza predominantemente identitaria, y que el origen étnico determina la interacción entre el mecanismo segregativo étnico y otros tipos de diferenciación presentes en la expresión pública del partido de derecha radical analizado. Palabras clave: Vox; discurso político; inmigración; diferenciación étnica; análisis del contenido; derecha radical 
Abstract. Ethnic selectivity in Vox's migration discourse: between pragmatism and essentialism

The political irruption of the radical right-wing party Vox in the Spanish political system has opened new spaces for academic research, one of the most pertinent being the study of its migration discourse. Starting from the central hypothesis of the existence of a differentiated discourse on immigration based on ethnic origin, the study aims to determine its relevance, orientation and argumentation. To carry out this research, a qualitative methodology has been chosen through the application of content analysis and the causal chain method to a sample of documentary and audiovisual sources. The results of this study reveal that Vox uses a predominantly identity-based bimodal ethnic differentiation discourse and that ethnic origin determines the interaction between the ethnic segregation mechanism and other types of differentiation present in the public expression of the radical right-wing party analyzed.

Keywords: Vox; political discourse; immigration; ethnic differentiation; analysis content; radical right

\section{Sumario}
1. Introducción
5. Resultados
2. Marco teórico
6. Conclusiones
3. Estado de la cuestión
Financiación
4. Datos y medición
Referencias bibliográficas

\section{Introducción}

La extraordinaria irrupción de Vox en el sistema de partidos español en los últimos años ha supuesto la incorporación de nuevos discursos políticos, hasta el momento marginados de la agenda pública (Anduiza, 2018). Uno de ellos es la politización de issues relacionados con la cuestión migratoria. En este artículo se pretende arrojar luz sobre dicha expresión pública de Vox en materia migratoria, habida cuenta de que este partido presenta un discurso propio respecto a los demás partidos nacionales que requiere un estudio específico, debido a sus singularidades y sus matices en cuanto a su posible rechazo del fenómeno migratorio en España. La justificación de tal investigación reside en dos argumentos fundamentales.

En primer lugar, resulta del propio aumento de la importancia del fenómeno migratorio y sus consecuencias sociales y económicas. En efecto, pese a un leve descenso en el periodo posterior a la Gran Recesión, el porcentaje de extranjeros empadronados en España de la población total ha pasado del $1,6 \%$ en 1998 al 10,71 \% en 2019 (INE, 2019). Esta población extranjera procede mayoritariamente de América Latina y Marruecos y, en mucho menor medida, de Rumanía, China y otros lugares, con un aumento en el periodo poscrisis del flujo de inmigración de los latinoamericanos de forma mucho mayor - de un $18 \%$ en 2013 a un $38 \%$ en 2019-al resto de orígenes (INE, 2019). 
En segundo lugar, es fruto del impacto en los outputs de los sistemas políticos de un mayor apoyo a los partidos de derecha radical en diversos países europeos, que está vinculado al discurso de tales actores sobre la inmigración, un discurso capaz de generar realidad social (Olmos, 2007). En España, Vox es el único partido relevante que cabe clasificar como de derecha radical (Ferreira, 2019), importante en la reciente transformación de los sistemas de partidos nacional y autonómicos. La oferta política del citado partido desde el nativismo y el nacionalismo impone la obligación de seguir profundizando en su discurso político, pues se advierte la ausencia de suficientes estudios centrados en su discurso étnico.

A propósito de esto último, este estudio trata de examinar la posible vinculación que existe entre el discurso migratorio de Vox y el discurso étnico. Con ello, se pretende abordar un vacío en la literatura e indagar, en concreto, varias cuestiones derivadas de la hipotética existencia de un discurso de diferenciación étnica en la concepción de la cuestión migratoria de Vox: ¿cuál es su grado de relevancia?, ¿cuál es su orientación discursiva? y ¿cómo se argumenta? La importancia de analizar la existencia y modulación del discurso de diferenciación étnica se deriva no solo de la inexistencia de estudios específicos sobre la expresión pública de Vox en materia migratoria, sino porque implicaría un avance en el perfeccionamiento de las etiquetas de antimigratorio o xenófobo para calificar el discurso migratorio de Vox.

\section{Marco teórico}

Desde hace décadas es recurrente señalar el auge de los estudios sobre el discurso político en los estudios politológicos. De la multitud de preguntas de investigación y de las múltiples aproximaciones posibles, cabe discernir tres grupos de análisis (Alonso et al., 2012: 13): aquellos que describen el discurso político (Leonisio, 2013; Helbing, 2014), aquellos que tratan de determinar sus causas (Adams et al., 2009; Ezrow et al., 2010) y aquellos que indagan en torno a sus efectos (Llera et al., 2017). Este trabajo no entra en determinar si, por ejemplo, la situación económica, el retroceso del estado o la democratización suponen factores de auge de la relevancia del discurso migratorio (Nederveen, 1996), o en la evaluación del impacto de las ofertas políticas antiinmigración en las políticas públicas (Akkerman, 2018), sino que se detiene, puesto que tanto el objeto de estudio como el enfoque categorial son relativamente novedosos, en estudiar descriptivamente el discurso de Vox en torno a la inmigración y, particularmente, en si ese discurso utiliza —en qué sentido y con qué razones- la estrategia de diferenciación étnica. No obstante, el análisis de las razones entra en consideraciones de causas o consecuencias, por la propia dinámica argumentativa del discurso político.

Los partidos políticos pueden adoptar variadas estrategias. Siguiendo a Steengergen y Scott (2004), existen dos teorías. Por un lado, la teoría espacial asume que las formaciones evolucionan en virtud de la posición de los votantes y se sitúan dentro de un espacio político dado. Por otro lado, la teoría de 
la relevancia considera que los partidos utilizan no tanto el posicionamiento opuesto como el énfasis selectivo y seleccionan aquellos temas y enfoques que les posicionan con ventaja competitiva. Esta investigación no aborda simplemente un análisis de la relevancia de un tema dentro de un discurso dado, sino que profundiza en el mismo estudiando la relevancia de una posición concreta - la diferenciación étnica-, sus características u orientación y la argumentación que lo sostiene. Es decir, se asume la teoría de la relevancia, pero no en cuanto al énfasis selectivo temático, sino posicional, en la medida en que no solo la temática de la inmigración puede no abordarse en un momento dado, sino que la posición de la diferenciación étnica puede no sostenerse siempre y puede tener diferente orientación y argumentación con el tiempo, ya sea por la posición de los votantes, la agenda, etcétera.

Dicho esto, y en cuanto al discurso migratorio, hay un tipo de expresión pública que se ha denominado ethnic politics o política étnica. La política étnica se define como aquella situación en la cual los políticos movilizan sus apoyos sobre la base de la apelación a la identidad étnica (Lynch, 2015). Existiría entonces una "política del discurso" sobre la inmigración, es decir, una expresión pública sobre el fenómeno migratorio que se constituye en acto político y que, por tanto, no es comprensión, sino acción (Zapata-Barrero, 2007).

Tal discurso migratorio, en su dimensión étnica, puede estar constituido por tres elementos. En primer lugar, se incluyen las categorías étnicas, como lengua, dialecto, ropa, costumbres, religión o raza. En segundo lugar, destaca la comunidad étnica o etnicidad, que es el dispositivo para garantizar la cohesión interna de la comunidad y la diferenciación nosotros/ellos. La etnicidad, en cualquier caso, cabe comprenderla bien de forma esencialista, como algo dado y relativamente estático, o bien de forma instrumental, como algo construido y relativamente variable (Nederveen, 1996). Y en tercer y último lugar, se encuentra el etnonacionalismo, que es esa comunidad étnica pero politizada (Nederveen, 1996). Este último elemento, como propone el presente trabajo, también podría denominarse solidaridad endoétnica, ya que la politización de la propia comunidad étnica suele estar acompañada de un discurso migratorio de solidaridad endoétnica.

De este modo, la etnicidad implica una relación entre dos grupos y un mutuo proceso de etiquetado o enmarcamiento, lo que tiene consecuencias en la posición política, económica y social de los mismos (Nederveen, 1996). La particular historia política española ha posibilitado el mantenimiento de fuertes similitudes y nexos culturales e idiomáticos con los ciudadanos de diversos países de América Central y del Sur (Elliot, 2019). Es precisamente este tipo de elementos históricos los utilizados por los partidos de derecha radical en su expresión pública. En efecto, «los partidos radicales de derecha retratan a la nación como una comunidad orgánica premoderna y defienden su homogeneidad promoviendo la diferencia y la exclusividad" (Halikiopoulou et al., 2012: 510). En la medida en que los partidos de derecha radical promueven la diferencia de la nación propia a través del uso de relatos históricos, es posible hipotetizar que Vox tenga dos discursos de diferenciación étnica, uno para la 
población latinoamericana y otro para el resto, fundamentalmente integrado por la etnia magrebí. Así, se requiere la distinción de dos modalidades posibles de discurso migratorio de diferenciación étnica, una proactiva y otra reactiva, ya que, como se ha argumentado, si bien los partidos radicales de derecha promueven la diferencia y articulan, de este modo, un discurso migratorio reactivo hacia el diferente, el devenir histórico de España posibilita la ampliación de la propia comunidad nacional en el discurso de estas formaciones políticas, con la inclusión en la misma, además de los propios españoles, a aquellas poblaciones cuyos territorios tuvieron una relación con España. Ello requiere considerar como probable no solo un discurso de naturaleza reactiva hacia la inmigración, sino también un discurso migratorio proactivo dirigido específicamente hacia esas poblaciones. Por ello, se plantea la primera hipótesis del siguiente modo:

$\mathrm{H}_{1}$ : El discurso migratorio de Vox es de diferenciación étnica bimodal, una proactiva dirigida a legitimar la inmigración latinoamericana y otra reactiva dirigida a deslegitimar la inmigración del resto de orígenes étnicos.

Es necesario considerar adicionalmente que la etnicidad es tan solo una forma de diferenciación del yo/nosotros frente al otro/otros, que compite y negocia frente a otras modalidades. En efecto, «la negociación de la etnicidad en relación con otras formas de diferencia - como clase, género, edad, lugar, ideología - se da por sentada» (Nederveen, 1996: 30). Parece entonces plausible que tales formas, en plural, de diferenciación u otrerización pueden ser utilizadas individual o combinadamente en diversos grados y con diversas pautas de relación argumental. De este modo, y por establecer algunas modalidades posibles, un discurso migratorio puede estar basado únicamente en la diferenciación étnica, sea atenuada o fuerte, o bien estar compuesto por una diferenciación, sea atenuada o fuerte, combinada, por ejemplo, de etnia y clase, y que argumente, por ejemplo, que de cierta etnia cabe integración solo si es capaz de insertarse en ciertos niveles del mercado de trabajo. Por lo que, sea de forma atenuada o fuerte, hay formas de diferenciación principales y otras secundarias o vinculadas a las primeras.

Esas formas de diferenciación pueden integrarse dentro de un esquema comprehensivo. Así, y siguiendo a Helbing, que cita a Habermas, cabe distinguir tres tipos generales de marcos ${ }^{1}$ sobre la inmigración: los relacionados con la identidad, los moral-universalistas y los utilitaristas. Los frames del primer tipo se basan en valores inherentes a una comunidad dada, con objeto de preservar la homogeneidad cultural e identitaria o bien de ejecutar valores multiculturales. Los marcos del segundo tipo hacen referencia a principios morales universales como los derechos humanos. Y los frames del tercer tipo enfatizan el impacto económico, laboral, de seguridad o pragmático de la inmigración (Helbing, 2014). Con todo, este trabajo reelabora — con el procedimiento

1. Es común afirmar que un frame es «un esquema de interpretación que promueve una definición de problema particular o una interpretación causal» (Helbing, 2014: 22). 
Tabla 1. Frames y variables operativas posibles en el discurso migratorio

\begin{tabular}{llll}
\hline Frames & Identidad & Moralidad & Utilitarismo \\
\hline Variables & - Tradiciones/costumbres & - Valores nacionales & - Sexo \\
operativas & - Historia & - Ideología & - Edad \\
& - Soberanía/legalidad & & - Estatus económico \\
& - Amenazas culturales, & - Capacidades/habilidades \\
& como la islamización & de trabajo \\
& & - Capacidades/habilidades \\
& & tecno-sociales \\
& & - Criminalidad \\
\hline
\end{tabular}

Fuente: elaboración propia a partir de Helbing (2014).

que se detalla en el siguiente apartado- un esquema específico que incorpora marcos y variables operativas a través de los cuales se construye el discurso migratorio y, específicamente, el discurso migratorio de diferenciación étnica de Vox:

Se ha argumentado que el discurso de los partidos de derecha radical utiliza elementos identitarios en la construcción del esquema nosotros/otros. En efecto, los partidos de derecha radical defienden discursivamente el Occidente cristiano y su democracia liberal frente a la ideología y cosmovisión islámicas (Betz, 2013). Esta tesis sugiere la presencia relevante de componentes identitarios, es decir, culturales, históricos, idiomáticos, etcétera, en el discurso de diferenciación étnica de Vox. Por ello, es posible argumentar que esta expresión pública es predominantemente identitaria. Sin embargo, se ha observado que el apoyo a este tipo de formaciones políticas está vinculado también a factores socioeconómicos como el miedo a la globalización (Beauzamy's, 2013), por lo que es plausible afirmar, alternativamente, que el eje identitario del discurso de los partidos de derecha radical está relacionado con requisitos de tipo utilitario, particularmente en el caso de una visión positiva de cierto origen étnico, ya que los partidos tienden, según el modelo de elección racional, a asumir posiciones que maximicen su apoyo electoral en función de su propio espacio competitivo. En este caso, y politizada la propia comunidad nacional por los partidos de derecha radical, podrían existir incentivos a aceptar condicionalmente la inmigración procedente de territorios que tuvieran alguna relación en el pasado con España, ya que el electorado percibiría una contradicción entre un discurso migratorio exclusivamente reactivo y la politización habitual en estas formaciones políticas (Halikiopoulou et al., 2012: 510) de los ya citados nexos culturales e idiomáticos con diversos países de América Central y del Sur.

Así, se requiere la distinción de dos modalidades posibles de discurso migratorio de diferenciación étnica, una proactiva y otra reactiva. Este trabajo sostiene que, si bien las dos modalidades — proactiva y reactiva- del discurso de diferenciación étnica son fundamentalmente de naturaleza identitaria, la expresión pública de diferenciación étnica proactiva está vinculada discursi- 
vamente a requisitos de tipo utilitario. Por ello, la segunda y tercera hipótesis son las siguientes:

$\mathrm{H}_{2}$ : El discurso de diferenciación étnica proactivo de Vox está sostenido en una argumentación predominantemente identitaria, aunque vinculando la aceptación de la inmigración al cumplimiento de ciertos requisitos utilitarios.

$\mathrm{H}_{3}$ : El discurso de diferenciación étnica reactivo de Vox está sostenido en una argumentación predominantemente identitaria, sin vinculación al marco utilitario.

\section{Estado de la cuestión}

\subsection{Institucionalización politica de Vox en el sistema político}

La irrupción de Vox en el panorama electoral español no fue ningún acontecimiento insignificante en la historia política de España (Casal y Rama, 2019). Tras un contexto previo de progresión ascendente en el ámbito europeo de diversas fuerzas situadas en el extremo derecho del espectro ideológico (Casals, 2011), por primera vez una organización de la familia política de la derecha radical conseguía en España una confianza electoral tal que, actualmente, la sitúa como tercera fuerza política en el Congreso de los Diputados (Ferreira, 2019). Surgida como consecuencia de una escisión de antiguos cuadros políticos del Partido Popular, ${ }^{2}$ distanciados de la política de su antiguo partido en cuestiones de identidad nacional y cultural, Vox se presenta ahora como una formación con una oferta política propia.

Este espectacular auge de Vox en la política española se mide por su trayectoria electoral, desde las primeras elecciones generales a las que se presentó, en diciembre de 2015 , cuando cosechó un poco menos de 50.000 votantes (0,23\% de voto válido), hasta los últimos comicios de noviembre de 2019, en los que multiplicó su rentabilidad política por 7 . Ha pasado, pues, de los casi 50.000 votos en 2015 a prácticamente 3.500 .000 votantes $(15,08 \%$ de voto válido) en estas últimas elecciones. Actualmente, Vox es la tercera fuerza política en escaños en el Congreso de los Diputados y disputa la hegemonía en el espacio de la derecha y centroderecha al Partido Popular. Igual que en el panorama nacional, el auge de Vox también se ve representado en el ámbito local, autonómico y europeo. Según los investigadores Turnbull et al., (2020), este crecimiento exponencial de voto en las últimas elecciones ha sido, fundamentalmente, por la atracción electoral que ha supuesto en un perfil de votante masculino, con identidad nacional acentuada y, sobre todo, molesto con la situación sociopolítica actual.

Lejos de ser un acontecimiento más en el contexto político nacional, lo cierto es que supone un cambio político nada desdeñable, a tenor de la historia reciente del panorama político español: nunca antes una fuerza política de la

2. <https://cronicaglobal.elespanol.com/politica/el-entorno-de-vidal-quadras-crea-un-nuevopartido-de-cara-a-las-europeas-de-mayo_3899_102.html>. 
Gráfico 1. Evolución del porcentaje de voto válido a Vox en las elecciones generales de España (2015-2019)

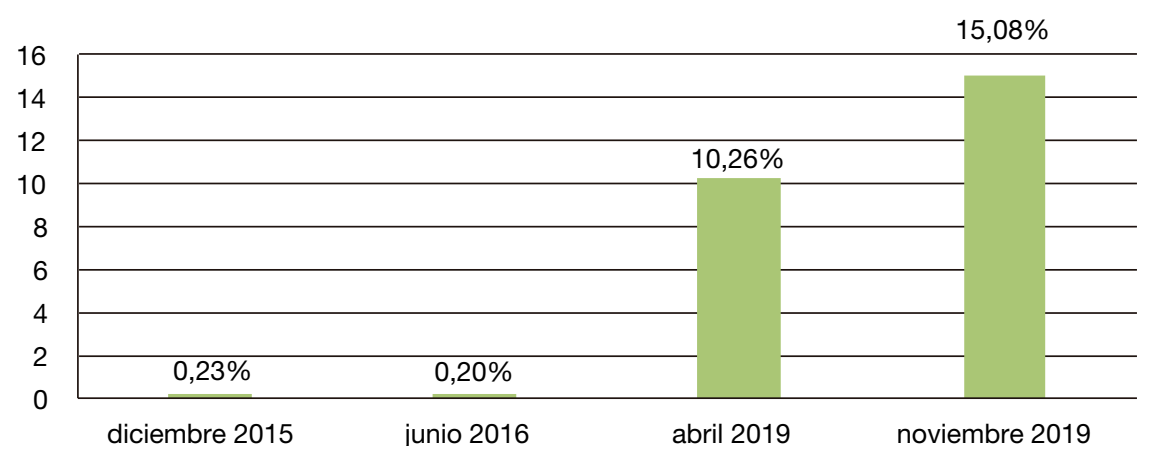

Fuente: elaboración propia a partir de datos del Ministerio de Interior.

derecha radical había conseguido tal afianzamiento electoral (Casals, 2000). En este sentido, España suponía un contexto político particular en una Europa cada vez más influenciada por partidos de esta familia política. Tan singular era la situación política española en cuanto a la emergencia de una oferta política de derecha radical que incluso se hablaba de la excepcionalidad española (Mendes y Dennison, 2020 Rubio, 2019). A diferencia de los países del entorno europeo, España, a pesar de contextos turbulentos de crisis económica, había sido inmune al crecimiento de fuerzas políticas de derecha radical. Ahora, como vemos, no sucede así. España ya cuenta con una fuerza política como Vox, cuya oferta política introduce en el panorama político nacional nuevos discursos y, definitivamente, una nueva agenda política (Anduiza, 2018).

Dicha excepción española se situaba en un contexto político europeo donde las fuerzas políticas de derecha radical estaban cuajando como organizaciones determinantes en el sistema político de sus países. Así, el Frente Nacional en Francia competiendo con Macron en las presidenciales de 2017; la Liga Norte de Italia recientemente en el seno del Gobierno italiano; Alternativa por Alemania como fuerza electoral en el país germano; Partido por la Libertad en los Países Bajos, y por último el UKIP en el Reino Unido son ejemplos de la creciente influencia electoral de esta familia política (Akkerman et al., 2016). Sin embargo, en España esta oferta política ha cuajado mucho más tarde, a pesar de la regular concurrencia electoral de formaciones autonomistas como PxC (Casals, 2009). El historiador Casals (2000), especialista en la extrema derecha española, se refiere a esta débil oferta política como una "presencia ausente», que apuntaba a una determinada demanda política en el ámbito social pero que en el electoral no conseguía institucionalizarse por diferentes motivos. La presencia de una consolidada derecha institucional que aglutinaba a diferentes familias políticas en su seno (Partido Popular), un discurso arcaico y anacrónico de las fuerzas políticas de extrema derecha y una débil organización política y orgánica parecían estar detrás de dicha frágil institucionalización política. Sin embargo, la irrupción de 
Vox quizás deba su éxito al hecho de distanciarse del concepto de dicha extrema derecha estigmatizada socialmente y, sobre todo, aprovecharse del vacío de oferta electoral en cuanto a issues como cuestiones nacionales o socioculturales (Mendes y Dennison, 2020). Más todavía, dicho éxito electoral quizás pueda estar relacionado con el abandono progresivo de la nostalgia franquista emprendido por la nueva extrema derecha española, que articula nuevos discursos y retóricas asimilables al contexto europeo en el caso concreto de Vox (Casals, 2009).

\subsection{Contextualización ideológica y discurso migratorio de Vox}

La literatura politológica sobre la extrema derecha diferencia entre derecha radical y derecha extrema. De acuerdo con Mudde (2019), cabría tal diferenciación entre ambos tipos de formación tanto por la orientación de la estrategia política a la hora de llegar al poder como por los objetivos políticos. Vox, como formación política, se situaría ideológicamente como partido de la familia de la derecha radical. Sin entrar todavía en la necesaria contextualización ideológica de Vox, cabe afirmar, antes que nada, que, mientras que la derecha extrema rechaza la democracia como sistema político, la derecha radical, asumiendo los postulados y principios procedimentales de la democracia, participa de los mismos con una oferta política crítica con el carácter liberal del sistema democrático: atacando los presupuestos liberales del pluralismo político y cultural, así como negando el derecho de las minorías (Mudde, 2000).

En cuanto a los elementos articuladores de la ideología de Vox, cabe sostener que es una organización política nacionalista española, para la cual es central la defensa de la identidad nacional española en su discurso político (Acha, 2019; Acha et al., 2020; Turnbull, 2019). Además, según el historiador González (2019), experto en la derecha española, Vox se adscribe a las corrientes ideológicas del liberalismo conservador y la derecha identitaria, pues conviven en su discurso ideas del conservadurismo social y cultural con el liberalismo económico. Así, en términos generales, se sitúa en el polo «tradicional/autoritarismo/nacionalismo» de la conocida como escala GAL-TAN (Hooghe et al., 2002).

Caracterizando su discurso conservador, pesa mucho su defensa de la familia tradicional y el rechazo al cambio sociocultural y a la ideología de género (Alonso, 2020; Ferreira, 2019). De acuerdo con Ferreira (2019), la ideología de Vox se puede enmarcar en un fuerte discurso nacionalista, autoritario, tradicionalista, nativista y neoliberal. Como se ve, destaca igualmente en su discurso el nativismo y la impugnación del modelo migratorio español, y se reafirma en una estrategia discursiva abiertamente anteislámica y contraria a los presupuestos del multiculturalismo (Ferreira, 2019).

Sumado al nativismo, su carácter autoritario y determinados rasgos populistas en su discurso hacen de Vox un partido alineado con la derecha radical europea (Mudde, 2007). De hecho, siguiendo a Anduiza (2018), Vox inaugura una forma de hacer política atravesada por un sistema de ideas autoritario, que converge con las tradicionales posiciones punitivistas de la nueva extrema 
derecha europea (Norris, 2009; Rovny, 2013). Sin embargo, respecto a la familia política europea, subyacen diferentes singularidades en el discurso de Vox: mientras que los partidos de esta familia política son destacadamente populistas, Vox - que sí recoge parte del discurso europeo populista sobre todo en inmigración-, no resulta ser un partido con un discurso que se pueda catalogar como marcadamente populista (Ferreira, 2019; Rubio, 2019; Anduiza, 2018). La cercanía que muestra con las elites empresariales del país, sumada a su defensa de una política económica neoliberal, aleja a Vox de las posiciones populistas de sus equivalentes europeos, quienes sí dividen explícitamente entre el pueblo y la elite del país. Sin embargo, contrariamente a esto y siguiendo los planteamientos de Mudde respecto al populismo, el investigador Turnbull (2019) define a Vox como un partido populista dada su nostalgia por una España grande del pasado a recuperar. Por otro lado, su posición a favor del neoliberalismo económico contrasta significativamente con las posiciones de la derecha radical europea (Ferreira, 2019).

Por último, es pertinente destacar la principal convergencia — que vertebra asimismo nuestra investigación - entre Vox y los partidos de su familia política europea: el nativismo ideológico, arraigado en un ideario nacionalista étnico y xenófobo. Vox emplea este discurso, central en la derecha radical europea (Ivarsflaten, 2008), al mismo tiempo que recurre a otros de cuestión territorial y nacional, como es la idea de España y la recuperación de un estado centralizado contrario a las pretensiones secesionistas de vascos y catalanes (Acha, 2019).

Dicho esto, el discurso nativista de Vox, aun así, es predominante, centrado, como el de sus equivalentes europeos, en la defensa de la seguridad nacional, la identidad nacional frente al multiculturalismo, el endurecimiento de las políticas de integración y la promoción de un estado social nativista (Turnbull, 2019; Cheddadi, 2020). La criminalización de la población inmigrante, especialmente colectivos como el de los menores extranjeros no acompañados, el rechazo al otro diferente, sobre todo de otras etnias, y la articulación de un discurso abiertamente islamófobo contrario a la expresión cultural o a la temida invasión islámica de España son elementos igualmente centrales en el discurso migratorio de Vox (Ferreira, 2019). Es precisamente esta caracterización del discurso migratorio de Vox como nativista lo que confiere relevancia a la presente investigación, ya que perfecciona la simple adjudicación de las categorías antiinmigratorio y xenófobo al discurso del partido político analizado.

\section{Datos y medición}

Para lograr responder a las preguntas de investigación expuestas, se requiere definir qué método utilizar, las dimensiones analíticas y variables que se tendrán en cuenta, la delimitación temporal y espacial y los documentos y datos.

En primer lugar, dentro de los estudios sobre el discurso, se encuentra el análisis del discurso migratorio y, concretamente, el análisis ideacional del mismo. En general, «el análisis del discurso no es un método, sino un campo de estudio amplio y multidisciplinario de las humanidades y las ciencias sociales» 
(Dijk, 2018: 227). Así, cabe la utilización de diversos métodos (Sayago, 2014), como «análisis de contexto, gestos, sonidos, sintaxis, significado, retórica, actos de habla, interacción, conversación, narrativa, argumentación o géneros como reportajes de noticias o debates parlamentarios, cada uno, nuevamente, con métodos y enfoques más específicos» (Dijk, 2018: 227). Esta investigación utiliza una aproximación cualitativa de tipo lingüístico y transversal al discurso político acerca de la migración. Se aplica una aproximación lingüística para incluir tanto la dimensión informacional —es decir, la relevancia de la información contenida - como la dimensión hermenéutica — es decir, la interpretación del sentido o significado que el sujeto dio al texto- (Alonso, 1998), y se utiliza una aproximación transversal para la identificación sistemática de todas dimensiones analíticas en los textos sujetos a estudio (Sayago, 2014). De forma adicional, se utiliza el método de la cadena causal (Ferreira, 2019) en el abordaje de la tercera dimensión analítica (argumentación), con el objeto de determinar la articulación de los razonamientos utilizados para sostener el discurso de diferenciación étnica. Así, en el segundo subapartado del capítulo de resultados, a través del método de la cadena causal, se analiza la jerarquía, de acuerdo con la dirección de la propia argumentación, de las diferentes dimensiones de diferenciación étnica presentes en el discurso migratorio de Vox.

En segundo lugar, es habitual señalar que en el análisis de contenido se tratan los textos para extraer dos informaciones diferentes: el énfasis que se da a diversos temas (saliency, en inglés) y la posición política (the direction, en inglés) del actor autor del texto (Pennings y Keman, 2002). Sin embargo, y de forma aditiva, el análisis cualitativo es capaz de captar la argumentación y la propia articulación de los razonamientos. Por ello, las dimensiones analíticas del discurso de diferenciación étnica son tres: relevancia, orientación y argumentación. Así, interesa identificar el peso en el discurso sobre la inmigración de Vox de esa estrategia selectiva, hacia qué origen étnico se dirige esa estrategia - si existiera orientación, bien proactiva o reactiva, como se deriva de la discusión realizada en el marco teórico-y qué razones, en caso de existir, se esgrimen —así como su articulación- para sostener tal discurso.

En el caso de la relevancia, se despliega la batería de frames y variables operativas potencialmente utilizables en un discurso político sobre la migración. Para la determinación de los frames y variables operativas, se ha seguido una estrategia deductiva y, a la vez, inductiva, al utilizar la propuesta de Helbing (2014), que parte de Habermas (2013), complementada con los marcos interpretativos y variables que surgen del propio análisis de los textos. Como se ha argumentado, tales variables pueden configurar diversos tipos de diferenciación o identificación. Así, se han recopilado todas las referencias del discurso migratorio de Vox y se ha analizado si cada tipo de diferenciación o identificación es relevante o residual.

En lo relativo a la orientación, con las mismas referencias se ha procedido a analizar cada unidad de significado para identificar si existe o no discurso de diferenciación étnica, con qué dirección, si es explícita o no y, en caso de ser explícita, si es favorable o contraria a tal orientación. 
En la última dimensión analítica, relativa a la argumentación, y del mismo modo que en el caso de la relevancia, se ha procedido a estudiar, mediante el método de la cadena causal, los patrones causales que originan y ordenan cada tipo de diferenciación o identificación, lo que permite identificar la presencia de cada frame y su relevancia o naturaleza residual.

En tercer lugar, la delimitación espacial se acota, por el objeto de estudio escogido - cuya selección se ha justificado previamente-, a España y, en concreto, al partido político Vox. En términos temporales, y como se ha expuesto, el auge de Vox comenzó a partir de las elecciones autonómicas de la Comunidad Autónoma de Andalucía de diciembre de 2018, por lo que el periodo de análisis será desde el primer congreso de Vox, previo a las citadas elecciones autonómicas, hasta el momento de realización de la investigación.

En cuarto y último lugar, hay diversos tipos de textos, intervenciones y medios que potencialmente podrían ser de interés para la investigación. Sin embargo, y para garantizar la viabilidad de la investigación, debe hacerse una selección - una muestra - de tales recursos y atender así a una selección de fuentes documentales. Este trabajo utiliza dos géneros del discurso migratorio (Dijk, 2018): el discurso en los medios y el discurso político. Así, resultan tres tipos de fuentes: discurso parlamentario o institucional, discurso electoral y discurso en medios de comunicación. El criterio de selección ha sido múltiple. Primero, en cuanto a su contenido y siguiendo los criterios de selección de Leonisio (2016), son materiales que comprenden tanto intervenciones generalistas como las relacionadas con temáticas referentes a lo estudiado, garantizan tener un discurso oficial proferido por un portavoz reconocido y autorizado, representan al partido en su conjunto y cubren el periodo de tiempo completo a analizar. Segundo, y en cuanto a su dimensión temporal, cubre no solo, como se ha afirmado, todo el periodo de análisis, sino que este se corresponde con el periodo de mayor vigor electoral e institucional del partido, desde el primer Congreso de Vistalegre, en octubre de 2018, hasta la actualidad, lo que confiere relevancia a la investigación. En tercer y último lugar, y en cuanto a su grado de cobertura, comprende el discurso de la formación política en todos sus ámbitos de actuación relevantes: los espacios parlamentario o institucional, electoral y mediático.

Concretamente, se han seleccionado las siguientes fuentes documentales: programas electorales, discursos en las sesiones de investidura del presidente del gobierno, intervenciones de diputados en el pleno y en la Comisión de Trabajo, Inclusión, Seguridad Social y Migraciones de la Cámara Baja (Congreso de los Diputados), intervenciones de senadores en la Cámara Alta (Senado) y entrevistas monográficas a destacados dirigentes políticos de Vox. Dicha muestra, ordenada en función del ámbito de actuación del partido Vox, se compone de los siguientes documentos y contenidos audiovisuales:

a) Ámbito parlamentario o institucional

— Sesión de investidura del presidente del gobierno de julio de 2019 (2225/07/2019). 
— Sesión de investidura del presidente del gobierno de enero de 2020 (0407/01/2020).

- Comisión de Trabajo, Inclusión Social y Migraciones (15/04/2020).

- Pleno del Congreso de los Diputados - Debate sobre el IMV $(10 / 06 / 2020)$.

- Comisión de Trabajo del Senado - Comparecencia del ministro José Luis Escrivá (18/06/2020).

- Exposición de motivos de la moción de censura al Gobierno de España (08/10/2020).

- Moción de censura al Gobierno de España (21/10/2020).

- Actividad parlamentaria de Vox en el Senado (todo el periodo).

b) Ámbito electoral

— Programa electoral «100 medidas para la España Viva» (07/10/2018).

- Acto de Vox «Vistalegre España Viva» (07/10/2018).

— Acto de Vox «Vistalegre Plus Ultra» (06/10/2019).

- Acto de Vox «Vistalegre La Alternativa» (8/03/2020).

- Documento «Diez medidas urgentes para salvaguardar la salud y la economía de los españoles» (31/03/2020).

c) Ámbito mediático

- Entrevista a Santiago Abascal, presidente de Vox, en Cuestión de poder de NTN24 (29/02/2020).

- Entrevista a Iván Espinosa de los Monteros, portavoz del Grupo Vox en el Congreso de los Diputados, en Jaime Bayly Show de NTN24 $(04 / 03 / 2020)$.

\section{Resultados}

Este apartado expone los resultados del análisis propuesto en la cuarta sección. Como se ha señalado, el objetivo es analizar tres aspectos acerca del discurso de diferenciación étnica presentes en Vox: su grado de relevancia, su orientación discursiva y su argumentación. Así, este apartado irá desgranando el estudio de campo realizado subdividiéndose para dar respuesta a tales preguntas de investigación.

\subsection{Relevancia del discurso de diferenciación étnica}

En primer lugar, debemos establecer el grado de relevancia del discurso de diferenciación étnica en Vox desde su primer congreso, celebrado el 7 de octubre de 2018. En este punto no es necesaria ni la diferenciación entre las orientaciones proactiva y reactiva hacia el fenómeno migratorio ni referencias a su argumentación, pues estas se cubrirán en los siguientes apartados.

En el discurso de Vox sobre la inmigración, hay un componente elevado de diferenciación, tanto en el lado proactivo como reactivo. Como se demuestra 
en el contenido subsiguiente, esta diferenciación no es exclusivamente étnica, sino que hay otros motivos de segregación o de identificación frente a otros. Es más, en el tercer subapartado, dedicado a la argumentación, se evidencia que este tipo de diferenciación está ligado a otras modalidades. Así, se pueden establecer varios tipos de identificación o diferenciación presentes: étnicacultural, legal, ideológica-política, económica, securitaria e higiénico-sanitaria. El objetivo es discernir individualmente su naturaleza relevante o residual en el conjunto del discurso migratorio de Vox.

La diferenciación étnico-cultural incluye aquellas frases dirigidas a señalar diferencias por motivos étnicos, históricos o culturales (lengua, religiosidad y costumbres). Esto tiene una presencia relevante. El partido asume positiva y frecuentemente el ámbito de la hispanidad o iberosfera, que liga a las poblaciones de países de tal espacio. Así queda patente cuando se expresa que «lo decimos [...] desde la convicción de que tenemos el deber de ayudar a nuestros compatriotas y hermanos hispanoamericanos» (Vox, 2020). Ese espacio, que tiene componentes de fusión histórica, ya que «el mestizaje, ya desde el primer viaje, fue la clave del desarrollo de la cultura hispánica, desde Cortés a Ojeda» (Senado, 2020a), es definido en términos culturales: «Lo decimos desde la hermandad con todas esas naciones con las que compartimos cultura, identidad y lengua» (Vox, 2020). Sin embargo, también se observa en este punto otra dimensión étnico-cultural que se definirá en el apartado 5.b., cuando el partido destaca que «la inmigración ha de ser [...] integrable, con adaptación a nuestra cultura e idiosincrasia» (Senado, 2020a) y que "nos quieren calladas ante las discriminaciones machistas de otras culturas, como el Islam» (Vox, 2019).

La diferenciación legal hace referencia a todas aquellas expresiones que diferencian entre el nacional y el inmigrante o bien entre el inmigrante legal y el inmigrante ilegal. Este tipo tiene una presencia relevante. Así se evidencia cuando se afirma que «en Vox, por supuesto, nos oponemos a la inmigración ilegal» (Congreso de los Diputados, 2019). Dicho de otro modo, el partido exige que «la inmigración ha de ser legal» (Senado, 2020a), y que, aunque sea un fenómeno necesario, debe exigirse en todo momento ese requisito: «Necesitamos una inmigración [...] que llegue a España de manera ordenada y legal» (Senado, 2020a). Cumplido ese requisito, el inmigrante entra en una zona de aceptabilidad. Así, «en Vox manifestamos claramente nuestro respeto y consideración hacia todos aquellos inmigrantes que han llegado o llegan a España por los cauces legales» (Senado, 2020b).

La diferenciación ideológico-política es un grupo de elementos discursivos que identifican positivamente por motivos ideológicos. Este tipo tiene una presencia residual. El partido político de derecha radical analizado utiliza discursivamente una identificación entre España y los pueblos del ámbito hispano. Así se evidencia cuando se afirma que «hoy nos dirigimos también a todos nuestros hermanos de Hispanoamérica, a los que los distintos Gobiernos de España han abandonado a los pies de la bota de los dictadores» (Vox, 2018a). Unos hispanoamericanos que no solo «están viviendo aquí huyendo de las dictaduras que tanto enaltecen sus líderes» (Senado, 2020a), sino que 
aprecian la labor de Vox: «No nos imaginábamos que había tantos hermanos hispanoamericanos al otro lado del Atlántico viéndonos con tanta ilusión, con tanta esperanza, deseando emular lo que nosotros estamos haciendo en España» (Vox, 2020). En conjunto, el partido propone construir «una alternativa que restaure los lazos de unión y hermandad de la Iberosfera y de todo el orbe hispánico, derrotando a las narcodictaduras y creando una gran alianza de naciones hermanas, de naciones hermanas [...] que quieren vivir en paz, en democracia, en libertad y en prosperidad» (Vox, 2020).

La diferenciación económica hace referencia a aquellas expresiones que diferencian por motivos económicos y laborales. Este tipo tiene una presencia relevante. El hecho del trabajo es un criterio de segregación claro, expresado tanto de forma positiva como negativa. De forma positiva, el partido afirma que "queremos ciudades [...] donde quienes vengan a trabajar de forma legal reciban acogimiento" (Vox: 2018a). Dicho de otro modo, "no está mal defender que aquellos que han llegado con intención de trabajar, esforzarse y contribuir a nuestro país tengan también acomodo» (Vox, 2018a). De forma negativa, se destaca el efecto en los recursos nacionales. Es evidente tal dimensión discursiva al afirmar que «nuestro Estado del Bienestar es incompatible con una política irresponsable de fronteras abiertas» (Vox, 2018a). En efecto, para el partido analizado la inmigración detraería recursos a los nacionales. Así se deduce del siguiente fragmento: «Díganselo al pueblo español: que van a desmantelar las fronteras y que a partir de ahora compartiremos nuestros recursos con todo habitante que desee o que necesite instalarse a vivir entre nosotros» (Congreso de los Diputados, 2019). Concretamente, el fenómeno migratorio supone una tensión para el sistema de ayudas públicas. Así, se destaca «esa inmigración ilegal que no viene a España para engrandecerla, sino para exigir prebendas, que miles y miles de españoles no tienen cuando deberían ser los primeros en recibirlas» (Vox, 2018a).

La diferenciación securitaria incluye aquellas frases que segregan por motivos de actitudes o actos de delincuencia común o contra la frontera nacional. Este tipo tiene una presencia relevante. Una parte importante de esta segmentación se refiere a actos de violencia o agresión sexual contra la mujer y su escaso tratamiento por el discurso político habitual. Así se evidencia cuando se afirma que «en veinte horas de debates no ha habido ni un solo segundo empleado en esta Cámara para denunciar la plaga de violaciones en manada que se han cometido en los primeros días de este año, fundamentalmente por extranjeros» (Congreso de los Diputados, 2020a). Así mismo, Vox denuncia el «ataque» a la frontera nacional recurrentemente: «Otra vez decenas de ciudadanos extranjeros han asaltado nuestra frontera, golpeando e hiriendo a nuestros guardias civiles y atacando nuestra soberanía» (Congreso de los Diputados, 2019). El partido propone que estos inmigrantes que cometen «delitos graves sean deportados a sus países de origen, con los que, por cierto, habrá que llegar a acuerdos para que cumplan allí su condena y para que no regresen jamás» (Congreso de los Diputados, 2019). En conjunto, en el siguiente fragmento se resumen los tipos delictivos que el partido analizado asocia a la inmigración: 
"Queremos lugares y ciudades vivibles, donde se pueda vivir y prosperar y no queremos ciudades que nuestros políticos cobardes han permitido que prospere la inmigración ilegal, las mafias, el narcotráfico o el salafismo» (Vox, 2018a).

Por último, la diferenciación higiénico-sanitaria es un grupo de elementos discursivos orientados a diferenciar por hábitos personales y culturales de tipo higiénico-sanitario, que conllevan riesgos de contagio tanto de enfermedades comunes como de la COVID-19. Este tipo tiene una presencia residual y presenta una intensificación reciente a raíz de la pandemia. En esta segmentación, Vox presenta habitualmente la duda: «No hay seguridad sanitaria sobre si entran portadores de graves enfermedades contagiosas» (Vox, 2018a). Además del cuestionamiento de la inmigración por su mayor propensión al contagio de enfermedades, derivada de sus diferentes hábitos personales y culturales higiénico-sanitarios, Vox señala la falta de previsión en el control de este riesgo. Así, un senador del partido afirma en sede parlamentaria que «ambos hechos están provocando que en Murcia haya una situación de importante riesgo sanitario al no poderse controlar a estas personas sanitariamente por falta de efectivos y material sanitario para realizarles las pruebas del coronavirus» (Senado, 2020b). En efecto, en esta dimensión segmentativa no solo es frecuente la interpelación al gobierno - como cuando se pregunta: «¿Cuáles son los protocolos de seguridad que se realizan para garantizar que los inmigrantes ilegales que llegan a las costas españolas no están infectados con el COVID19?» (Senado, 2020a)—, sino que se imputa al mismo una doble vara de medir: «Pida perdón por permitir la entrada de miles de inmigrantes ilegales sin ningún tipo de control sanitario mientras impide trabajar a empresarios y a autónomos" (Senado, 2020a).

Como se ha señalado, estos tipos de diferenciación e identificación están incluidos en el listado de variables operativas del esquema adaptado de Helbing (2014) que este trabajo propone. Tan solo resta afirmar, en torno a los marcos que incluyen tales variables, que la evidencia recogida permite concluir que los frames con mayor presencia son los relativos a la identidad y al utilitarismo, mientras que el de moralidad es de relevancia residual.

Si bien es cierto que estos seis mecanismos argumentativos orientados a la diferenciación, bien sea en un plano nosotros frente a ellos o nosotros y próximos frente a ellos, están presentes en el discurso de Vox en el grado de relevancia señalado, es preciso afirmar que no aparecen inconexos. De este modo, podemos agrupar tales dimensiones segregativas observando su patrón causal, tal y como el discurso del partido analizado lo presenta. Estos patrones causales se desgranan en el segundo subapartado de resultados, dedicado a la orientación y argumentación del discurso de diferenciación étnica.

\subsection{Orientación y argumentación del discurso de diferenciación étnica}

En segundo lugar, es preciso analizar la orientación y argumentación del discurso de diferenciación étnica de Vox. Dividiremos la exposición, como se ha justificado en el marco teórico, entre las intervenciones de carácter proactivo 
y reactivo hacia el fenómeno migratorio. Esta división es clave, puesto que del análisis realizado se deduce la existencia en el discurso de Vox de una diferenciación asimétrica o disímil entre las expresiones con orientación proactiva y reactiva, aunque con un componente reactivo más acusado. Aunque se han apuntado en el subapartado 5.a. algunos razonamientos, patrones y ejemplos, en este punto cabe en algunos casos la repetición, en la medida en que sean relevantes en la exposición de la orientación y la argumentación del citado discurso de diferenciación étnica.

En el lado proactivo se observa una distinción étnica con orientación pragmática. Esta afirmación se basa en que, si bien existe una diferenciación étnica positiva en favor del espacio latinoamericano ${ }^{3}$ por motivos étnico-culturales, esta inmigración está supeditada en el discurso de Vox a las necesidades económicas, sociales y culturales del país. Así se expresa de forma clara al afirmarse que "por eso, cuando es necesaria, aceptamos especialmente la inmigración latinoamericana para España y como posible solución para Europa» (Congreso de los Diputados, 2019). Asimismo, ello queda patente en la siguiente referencia contenida en el programa electoral titulado «100 medidas para la España Viva»:

La inmigración se afrontará atendiendo a las necesidades de la economía española y a la capacidad de integración del inmigrante. Se establecerán cuotas de origen privilegiando a las nacionalidades que comparten idioma e importantes lazos de amistad y cultura con España. (Vox, 2018b)

Este tipo de inmigración es más aceptable para el partido por dos tipos de razones. En primer lugar, por similitudes ideológicas, como cuando se afirma que «hoy nos dirigimos también a todos nuestros hermanos de Hispanoamérica, a los que los distintos Gobiernos de España han abandonado a los pies de la bota de los dictadores» (Vox, 2018a). Este trabajo propone denominar este tipo de similitudes «etnonacionalismo» o "solidaridad endoétnica». En segundo lugar, y en la mayoría de casos, por similitudes de tipo étnico-cultural, que se refieren en la práctica a la lengua, cultura, historia e identidad social y cultural. En los siguientes términos hace referencia a ello el presidente de Vox, Santiago Abascal:

Sorprendentemente para algunos no tienen por qué ser los que están más cerca, si no los que pueden, por razones culturales, adaptarse a mejor entre nosotros. En ese sentido, la inmigración procedente de los países hermanos hispanoamericanos es una inmigración que tiende a integrarse con facilidad en la sociedad española. (NTN24, 2020)

Tenemos el gran ámbito de la Hispanidad, la Hispanosfera, que, a través de la lengua, la cultura, nos une a millones de personas en todo el mundo que son nuestros hermanos. [...] Esa es nuestra fuerza, esos deben ser nuestros aliados, con ellos debemos estar juntos, codo con codo para defender nuestra

3. Aunque también se argumenta positivamente de forma genérica en multitud de ocasiones. 
identidad, nuestra cultura, nuestra obra histórica y poder ser respetados por el mundo. (Vox, 2019)

Sin embargo, y como se ha señalado anteriormente, tales similitudes, si bien hacen más aceptable la inmigración latinoamericana, suponen en el discurso de Vox un elemento necesario pero no suficiente para aceptar la inmigración. De este modo, solo se alcanza la suficiencia en la aceptación de la misma al cumplir ciertos criterios, a los que se supedita la inmigración. Esto es claro al expresarse que «en Vox abogamos siempre por una inmigración legal, supeditada al interés económico, social y cultural del país» (Senado, 2020a).

En esta misma línea, el presidente de Vox realiza esta aclaración en la que supedita la inmigración deseada a las condiciones de posibilidad del país:

Es una cuestión de sentido común y de caridad bien entendida. Igual que yo soy padre de familia, lo primero que procuro es el bienestar de mis hijos, si me sobra algo quizás el de mis sobrinos, el de mis vecinos, y si me sobra más el de más gente. Pero parece que no tiene lógica procurar el bienestar de mis vecinos cuando no puedo procurar el bienestar de mis hijos. Entonces eso es lo que están haciendo los políticos españoles (NTN24, 2020).

Así, la inmigración, preferentemente latinoamericana, debe cumplir diversos requisitos, de naturaleza práctica y de conveniencia para la nación. Son varios los criterios establecidos en este caso. En primer lugar, hace falta cumplir con las normas jurídicas establecidas para que se considere inmigración legal. En este sentido, Vox afirma que «necesitamos una inmigración [...] que llegue a España de manera ordenada y legal y no forzando las puertas de entrada» (Senado, 2020a).

En segundo lugar, contempla venir a trabajar y contribuir junto a los nacionales a las cargas comunes. Esto es claro cuando se afirma que «queremos ciudades [...] donde quienes vengan a trabajar de forma legal reciban acogimiento como por ejemplo nuestros hermanos de la Hispanidad, que [...] vienen a integrarse y vienen a trabajar y a cumplir todos los requerimientos legales» (Vox, 2018a) y «de la misma manera que no está mal defender que aquellos que han llegado con intención de trabajar, esforzarse y contribuir a nuestro país tengan también acomodo» (Vox, 2018a).

En tercer lugar, es necesario comportarse de acuerdo a o con respeto a las costumbres nacionales. Así Vox afirma:

Nuestros abuelos tuvieron que marcharse, porque la situación del país no podía cubrir sus necesidades, y cuando marcharon, trabajaron y aprovecharon la oportunidad que se les dio para cumplir con dignidad un modo de vida para que su descendencia tuviera las oportunidades de las que ellos carecieron, cumpliendo con la legalidad y costumbres de aquellos países. (Senado, 2020a)

En definitiva, el conjunto de criterios de supeditación queda expresado explícitamente en la siguiente cita: 
Reitero que una inmigración debe estar sujeta a cupos y supeditada a intereses económicos, sociales y culturales del país que la acoge y jamás puede suponer un detrimento del Estado del Bienestar de los españoles. Se persigue directamente lo contrario: una contribución neta a nuestra economía en positivo, nunca en negativo y por exceso de subsidiación. La inmigración ha de ser legal, productiva, integrable, con adaptación a nuestra cultura e idiosincrasia, respetable y sumatoria, tal y como se exige a los españoles que emigran o emigraron. (Senado, 2020a)

Por otro lado, en referencia al postulado reactivo, cabe identificar una distinción étnica esencialista de consecuencias explícitas. Esta parte del discurso de Vox orientada a la reacción frente a la inmigración es de mayor relevancia y presencia que la proactiva y tiene como principal característica estar basada en motivos étnico-culturales. Este discurso no está dirigido explícitamente contra ninguna etnia, sino que en la mayor parte de los casos está construido de modo que se refiere implícitamente a la etnia magrebí o islámica, por los motivos que se arguyen. La argumentación de tal visión reactiva de la inmigración tiene varios ejes, ya identificados en el apartado 5.2: legal, étnico-cultural, ideológico, económico, delincuencial e higiénico-sanitario. Como ya están suficientemente descritos, solo resta detallar la articulación de los razonamientos empleada.

En términos globales, la visión reactiva de la inmigración del discurso de Vox tiene su origen, de forma paradójica, en la cara proactiva de su expresión pública hacia el mismo fenómeno. En otras palabras, a modo de contraespejo, la inmigración rechazada lo es por el diagnóstico contrario al adjudicado a la inmigración aceptada, sea latinoamericana o la referida genéricamente. Tal diagnóstico señalaba que la inmigración aceptable lo es por cumplir con los procedimientos legales de entrada, por su contribución económica a la nación o por su adaptación social y cultural. De modo contrario, el discurso de Vox afirma que la inmigración inaceptable, implícitamente magrebí o islámica, lo es por no poderse adaptar por su propio origen étnico a la estructura socioeconómica el país; es decir, no es posible que cumpla con los procedimientos legales de entrada, contribuya económicamente al común y se inadapte social y culturalmente.

En primer lugar, Vox considera que determinado flujo migratorio supone una invasión incontrolada. Así se deduce de la afirmación siguiente: «Otra vez decenas de ciudadanos extranjeros han asaltado nuestra frontera, golpeando e hiriendo a nuestros guardias civiles y atacando nuestra soberanía» (Congreso de los Diputados, 2019). Es más, esa invasión tendría un objetivo dirigido contra la nación: "Al final esa grave amenaza contra España y contra Europa se resume en lo que ya el dictador Gadafi dijo hace tiempo: seremos la invasión de Europa, pero no con las armas, sino con el vientre de nuestras mujeres. Eso es la invasión demográfica. Y eso no es otra cosa que una invasión por sustitución»(Vox, 2019). Tal visión de la invasión se completa con el factor higiénico-sanitario, pues se considera que los inmigrantes pueden ser un vector de contagio, tanto de enfermedades comunes como de la COVID-19. En efecto, «en Vox hace más de un año calificamos la oleada de inmigración ilegal 
como una invasión silenciosa y afirmábamos que se debían tomar medidas de inmediato ya que resulta una amenaza gravísima para la salud, la seguridad y la convivencia de los españoles» (Senado, 2020b). Esta percepción y análisis de la inmigración cabe denominarla punitivista, pues recurre a la fuerza y a la ley para abordar discursivamente el fenómeno.

En segundo lugar, el partido político analizado señala que las malas condiciones económicas de origen, unidas a una hipotética estrategia globalista, son las que causan el propio fenómeno migratorio. Este contraargumento de solidaridad se expresa nítidamente en la siguiente cita:

Esa amenaza exterior, esa invasión migratoria ilegal, fomentada por aquellos como Soros que les fuerzan a pagar grandes cantidades de dinero en sus países de origen. [...] Esas mafias del tráfico de las personas que les impulsan en ese viaje suicida en el que muchos pierden la vida y que luego, para los que logran sobrevivir, entrar en España y en el resto de Europa, les esperan las redes del tráfico de las personas, la prostitución, la droga, la delincuencia común, el tráfico de mercancías ilegales. Pero esas mafias tienen el apoyo y la connivencia dentro de España, con los gobiernos traidores que les facilitan la entrada, con los partidos acobardados que miran hacia otro lado en un silencio cómplice, y con esas pseudo-ONG regadas de dinero público que se benefician de la tragedia ajena. (Vox, 2019)

En efecto, el partido considera que esas condiciones de origen tienen dos consecuencias. En primer lugar, posibilitan la aparición de actitudes delincuenciales en la población inmigrante. Este escenario es rechazado: "No queremos ciudades que nuestros políticos cobardes han permitido que prospere la inmigración ilegal, las mafias, el narcotráfico o el salafismo» (Vox, 2018a). En segundo lugar, las malas condiciones iniciales, unidas al hipotético efecto llamada derivado del establecimiento de ayudas sociales, ${ }^{4}$ no solo no contribuyen al estado de bienestar nacional, sino que imposibilitan un mercado laboral de sueldos «dignos». Así, se afirma que:

Esa desestabilización económica que está llevando a que esa entrada masiva e ilegal al final caiga en las redes de las multinacionales para abaratar la mano de obra, porque aquellas personas estarán dispuestas a trabajar por cualquier condición laboral. Y eso es de lo que se quieren aprovechar. (Vox, 2019)

Dicha denuncia se ve acompañada por un pesimista diagnóstico anticipado sobre la promulgación de políticas sociales en España. Así, se destaca: «Es grave, muy grave, el tremendo efecto llamada que está provocando el anuncio del Ingreso Mínimo Vital en los términos en los que ustedes lo han planteado» (Congreso de los Diputados, 2020b).

4. Se afirma: «Ese efecto llamada, que supone igualmente que todo aquel que salta sabe que tarde o temprano va a recibir una ayuda económica y una vivienda social, que no hay para los españoles más necesitados» (intervención en el II Congreso Vistalegre Plus Ultra). 
En conjunto, poner en valor el diagnóstico de la no contribución económica de los inmigrantes supone una pretensión de transformar el debate público: de la migración como derecho humano a la migración sujeta de responsabilidades frente a la nación. La referencia de Espinosa de los Monteros, expuesta a continuación, es clarividente respecto al hecho de que en su discurso debe primar el interés de la nación por encima del cumplimiento de los derechos humanos: «Yo creo que las naciones tienen derecho a guardar sus fronteras. [...] Y a decidir quiénes son los que entran en su país, quienes, cuántos, cómo...» (NTN24, 2019). El presidente de Vox, igualmente, en una entrevista en el canal NTN24 (2020) se expresa en dichos términos: «Un país tiene que decidir qué tipo de inmigración recibe [...]. No solo en función de la procedencia, sino en función de las profesiones, necesidades del país. La inmigración tiene que regularizarse en función de las necesidades de la economía nacional».

En tercer lugar, Vox considera que los inmigrantes inaceptables son inadaptados sociales y culturales. Tal inadaptación se deriva de su propia cultura islámica. El discurso que construyen en torno a este aspecto refiere una serie de rechazos a esta cultura por varios motivos. En primer lugar, esto es debido a su visión de la igualdad entre el hombre y la mujer. Se afirma que tales culturas tienen "diferentes y a veces abominables ideas sobre la mujer» (Congreso de los Diputados, 2019), contrapuestas a la cultura nacional española: «No hay mujer más inteligente, más autónoma y más libre que la mujer española» (Vox, 2020). Será precisamente este aspecto cultural el que se relacione, en general implícitamente, con la imputación de una mayoría de las agresiones sexuales a extranjeros: «Señorías, no sirve de nada que ustedes oculten, porque son datos públicos, que el $69 \%$ de los varones imputados en violaciones grupales han sido extranjeros, pese a ser solo el $10 \%$ de la población» (Congreso de los Diputados, 2020a). En segundo lugar, se refiere a la tradición occidental de separación del ámbito político y religioso, al afirmar que «[las culturas remotas que introducen] ni siquiera contemplan una diferencia entre las leyes civiles y las ideas religiosas» (Congreso de los Diputados, 2019). Esta diferencia cultural permite al partido argüir la vinculación entre la inmigración magrebí y el salafismo, lo que completa la dimensión securitaria de su discurso.

En la construcción de dicho discurso de la inadaptación ejerce un papel importante el componente étnico-nacional. En efecto, la contraposición entre «la Europa multicultural [y] la Europa orgullosa de las raíces cristianas» (Vox, 2019) hace que se considere que «los enemigos de nuestra soberanía [...] desde sus posiciones globalistas quieren disolver la existencia de España en un magma multicultural» (Vox, 2019). Y el peligro para la nación en el discurso de Vox es el riesgo de que «alguien venga a decirnos cómo tenemos que vivir, cómo tenemos que rezar, cómo tenemos que comer y cuáles tienen que ser nuestras leyes» (Vox, 2019). De tal modo que el discurso clasifica la nación como capital básico de la supervivencia de la virtud cultural cristiana.

En la siguiente figura se presenta un cuadro marco de los mecanismos argumentativos y su articulación en función de su orientación proactiva o reactiva. 
Figura 1. Nexos causales del discurso de diferenciación étnica de Vox
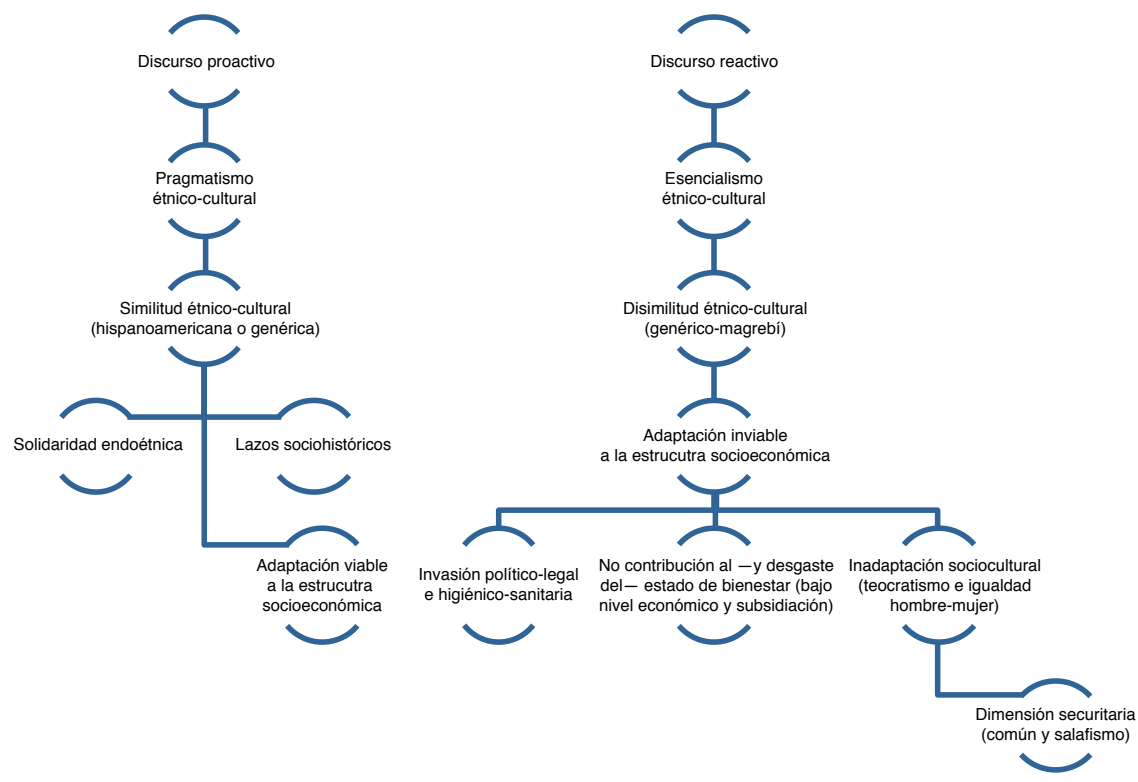

Fuente: elaboración propia.

En definitiva, de la observación de la figura 1 se desprende que existen dos visiones sobre la inmigración presentes en el discurso de Vox. Por un lado, se observa una perspectiva proactiva que podríamos denominar de distinción étnica con orientación pragmática. Así, una parte de la expresión pública del partido analizado asume una determinada inmigración de origen hispanoamericano por su similitud étnico-cultural, en distintas variables como la lengua, la cultura, la identidad y la historia, aunque las consecuencias de tales nexos aparecen generalmente implícitas. Tales similitudes, incluso, construyen un nuevo nexo identitario de tipo ideológico que este trabajo propone denominar solidaridad endoétnica. No obstante, la existencia de tales vinculaciones no es suficiente para promover la inmigración proveniente del área latinoamericana, pues está condicionada a su viabilidad en el proceso de adaptación a la estructura socioeconómica.

Por otro lado, existe una perspectiva reactiva que denominamos de distinción étnica esencialista de consecuencias explícitas. De este modo, otra parte de la expresión pública de Vox, más relevante en términos de su amplitud relativa, observa en la disimilitud étnico-cultural de cierta inmigración magrebí (citada generalmente de modo implícito) el factor de origen de múltiples consecuencias negativas para el país receptor: una invasión político-legal e higiénico-sanitaria, un desgaste económico del estado de bienestar nacional generador de desigualdades y la aparición de delincuencia, tanto común como vinculada al salafismo. Esa visión esencialista del discurso reactivo hacia la 
inmigración en la dimensión étnico-cultural provoca la práctica inexistencia de argumentos pragmáticos dirigidos a posibilitar la aceptación de inmigración magrebí. En definitiva, no existe una visión alternativa de esta inmigración, por lo que hay un rechazo frontal a la misma. Sin embargo, aunque el discurso construido no alude a dicha alternativa, también es cierto que hipotéticamente esta representación esté contaminada de variables socioeconómicas, por lo que la visión esencialista quizá pueda verse atenuada y reducida por una visión de clase social de estos inmigrantes. Pues una inmigración del mismo origen pero con diferente clase social a la mayoritaria, es decir, media o alta, puede, si no ser vista con diferentes ojos, sí con menor beligerancia que la actual.

\section{Conclusiones}

Este trabajo se ha propuesto estudiar la naturaleza del discurso migratorio de Vox y, en concreto, si esa expresión pública utiliza —en qué sentido y con qué razones- la estrategia de diferenciación étnica. Las tres hipótesis propuestas, que daban respuesta a las tres preguntas de investigación planteadas, han recibido respaldo con la evidencia empírica presentada.

En primer lugar, se ha comprobado que el discurso migratorio de Vox hace uso de diferentes mecanismos de identificación/segmentación: étnico-cultural, legal, ideológico, económico, securitario e higiénico-sanitario. Los de mayor relevancia, efectivamente, son los mecanismos étnico-cultural, económico, legal y securitario, y son de relevancia residual el ideológico y el higiénico-sanitario. Así, se demuestra que, aunque el discurso de Vox está ligado a una segmentación en términos étnicos, esta no es exclusiva, ya que convive con otras fuentes de diferenciación y segmentación como las anteriormente expuestas. En términos de la variante del modelo propuesto por Helbing (2014), se evidencia que los frames con mayor presencia son los relativos a la identidad y al utilitarismo, y el de relevancia residual es el de moralidad.

En segundo lugar, en términos de la orientación del discurso migratorio de diferenciación étnica, y comprobada su existencia, se ha evidenciado que el discurso migratorio de Vox es de diferenciación étnica bimodal. En otras palabras, su expresión pública en materia migratoria tiene dos modalidades, en función del origen étnico al que se dirige: una es proactiva, en la medida en que está orientada a legitimar la inmigración latinoamericana, y otra es reactiva, en la medida en que su objeto es deslegitimar la inmigración del resto de orígenes étnicos, particularmente el magrebí. Se ha expuesto, adicionalmente, que la modalidad reactiva es más relevante en términos relativos que la proactiva.

En tercer lugar, en cuanto a la argumentación de tal discurso de diferenciación étnica bimodal, se ha comprobado que existe una vinculación disímil entre los marcos más relevantes en función de la orientación del discurso. Así, si bien en la orientación proactiva no se encuentra vinculación causal entre el marco identitario y utilitario y se vincula la aceptación de la inmigración latinoamericana a ciertos requisitos prácticos, en la orientación reactiva sí exis- 
te, puesto que es la definición identitaria o étnico-cultural la que determina consecuencias negativas en el plano utilitario. De esta forma, se ha definido la postura proactiva como pragmatismo étnico-cultural y la postura reactiva como esencialismo étnico-cultural. Esto permite concluir que el mecanismo segregativo preeminente en el discurso migratorio de Vox es el étnico (frame identitario), al que cabe vincular causalmente o como criterio adicional de aceptación —en función de la modalidad proactiva o reactiva - diversos mecanismos diferenciadores del frame utilitario.

Por último, es pertinente agregar que esta investigación puede contribuir a abrir nuevas posibilidades y vías futuras para profundizar en el discurso de Vox sobre la inmigración. En primer lugar, en cuanto al contenido del análisis, se podría plantear la posible atracción discursiva entre el discurso reactivo étnico-cultural y un posible discurso de clase social en referencia a dichos inmigrantes. Es menester abrir nuevas hipótesis que puedan ser comprobadas, ya que el perfil del inmigrante indeseado por Vox es construido relativamente por características socioeconómicas o de clase social. En segundo lugar, en cuanto a la metodología, es posible aplicar técnicas cuantitativas de análisis de contenido para evaluar el peso de cada tipo de diferenciación étnica. En tercer y último lugar, en cuanto al campo de análisis, sería relevante realizar un estudio comparado con otros partidos de derecha radical europeos, para visualizar la diferente importancia, orientación y argumentación del discurso de diferenciación étnica.

\section{Financiación}

Esta investigación ha sido desarrollada gracias al Programa Predoctoral de Formación de Personal Investigador No Doctor del Departamento de Educación del Gobierno Vasco.

\section{Referencias bibliográficas}

ACHA, Beatriz (2019). «No, no es un partido (neo)fascista». Recuperado de <http:// agendapublica.elpais.com/no-no-es-un-partido-neofascista/>.

ACHA, Beatriz; INNERARITY, Carmen y LASANTA, María (2020). «La influencia política de la derecha radical: Vox y los partidos navarros». Methaodos. Revista de Ciencias Sociales, 8 (2), 242-257. $<$ https://doi.org/10.17502/mrcs.v8i2.384>

ADAMS, James; HaUPT, Andrea B. y STOLL, Heather (2009). «What Moves Parties? The Role of Public Opinion and Global Economic Conditions in Western Europe». Comparative Political Studies, 42, 5, 611-639. <https://doi.org/10.1177/0010414008328637>

AKKERMAN, Tjitske (2018). «Partidos de extrema derecha y políticas de inmigración en la UE». Anuario CIDOB de la Inmigración 2018, 47-62. $<$ https://doi.org/10.24241/anuariocidobinmi.2018.48>

AKKerman, Tjitske; LANGe, Sarah L. de y RoOduijn, Matthiis (2016). Radical RightWing Populist Parties in Western Europe. Into the Mainstream? Londres: Routledge. 
Alonso, Alba (2020). «El rol de la igualdad de género en la derecha populista radical». Recuperado de <http://agendapublica.elpais.com/el-rol-de-la-igualdad-de-generoen-la-derecha-populista-radical/>.

Alonso, Luis E. (1998). La mirada cualitativa en sociología. Una aproximación interpretativa. Madrid: Editorial Fundamentos.

Alonso, Sonia; Volkens, Andrea y Gómez, Braulio (2012). Análisis de contenido de textos politicos. Un enfoque cuantitativo. Madrid: CIS.

AnduizA, Eva (2018). «El discurso de Vox». Recuperado de <http://agendapublica. elpais.com/el-discurso-de-vox/>.

BEAUZAMY's, Brigitte (2013). «Explaining the Rise of the Front National to Electoral Prominence: Multi-Faceted or Contradictory Models». En: WODAK, Ruth; KHOSRaviNik, Majid y Mral, Brigitte (eds.). Right-Wing Populism in Europe. Politics and Discourse. Londres: Bloomsbury.

Betz, Hans-Georg (2013). «Mosques, Minarets, Burqas and Other Essential Threats: The Populist Restricting Islamic Symbols in Contemporary Europe». En: WODAK, Ruth; KhosraviNik, Majid y Mral, Brigitte (eds.). Right-Wing Populism in Europe. Politics and Discourse. Londres: Bloomsbury.

CASAL, Fernando y RAMA, José (2019). «Sartori, fragmentación y polarización política». Recuperado de <http://agendapublica.elpais.com/sartori-fragmentacion-ypolarizacion-politica/>.

CASALS, Xavier (2000). «La ultraderecha española: una presencia ausente (1975-1999)». Historia y Politica: Ideas, Procesos y Movimientos Sociales, 3, 147-174.

- (2009). "La renovación de la ultraderecha española: una historia generacional (1966-2008)». Historia y Politica: Ideas, Procesos y Movimientos Sociales, 22, 233258.

- (2011). «La extrema derecha europea: una tendencia ascendente». Anuari del Conflicte Social, 1, 389-401.

CHEDDADI, Zakariae (2020). «Discurso político de Vox sobre los menores extranjeros no acompañados». Inguruak. Revista Vasca de Sociología y Ciencia Política, 69, 57-77. <https://doi.org/10.18543/inguruak-69-2020-art04>

Congreso de los Diputados (2019). «Diarios de sesiones del 22 y 25 de julio de 2019».

- (2020a). «Diarios de sesiones del 4, 5 y 7 de enero de 2020».

- (2020b). «Diario de sesiones del 10 de junio de 2020».

Dijk, Teun A. van (2018). «Discourse and Migration». En: ZAPATA-BARrero, Ricard y YaLAZ, Evren (eds.). Qualitative Research in European Migration Studies. Cham: Springer.

EL ESPAÑOL (2014). «El entorno de Vidal-Quadras crea un nuevo partido de cara a las europeas de mayo». El Español. Recuperado de <https://cronicaglobal.elespanol. $\mathrm{com} /$ politica/el-entorno-de-vidal-quadras-crea-un-nuevo-partido-de-cara-a-laseuropeas-de-mayo_3899_102.html>.

Elliot, John H, (2019). España y su mundo, 1500-1700. Madrid: Taurus.

EzRow, Lawrence et al. (2010). «Mean Voter Representation and Partisan Constituency Representation: Do Parties Respond to the Mean Voter Position or to Their Supporters». Party Politics, 17 (3), 275-301. <https://doi.org/10.1093/acprof:oso/9780199572526.003.0006>

FERreirA, Carles (2019). "Vox como representante de la derecha radical en España: un estudio sobre su ideología». Revista Española de Ciencia Política, 51, 73-98. <https://doi.org/10.21308/recp.51.03> 
GONZÁLEZ, Pedro (2019). VOX. Entre el liberalismo conservador y la derecha identitaria. San Sebastián: La Tribuna del País Vasco.

Habermas, Jürgen (1993). Justification and Application. Remarks on Discourse Ethics. Cambridge: Polity Press.

Halikiopoulou, Daphne et al. (2012). «The paradox of nationalism: The common denominator of radical right and radical left euroescepticism». European Journal of Political Research, 51 (4), 504-539. <https://doi.org/10.1111/j.1475-6765.2011.02050.x>

HeLbING, Marc (2014). «Framing Immigration in Western Europe». Journal of Ethnic and Migration Studies, 40, 21-41. <https://doi.org/10.1080/1369183x.2013.830888>

Hooghe, Liesbet; MARKS, Gary y WiLson, Carole J. (2002). «Does left/right structure party positions on European integration?». Comparative Political Studies, 8, 965-989. <https://doi.org/10.1017/cbo9780511492013.008>

INE (2019). «Estadística de Migraciones». Recuperado de <https://www.ine.es/dyngs/ INEbase/es/operacion.htm?c=Estadistica_C\&cid=1254736177000\&menu=resul tados\&idp $=1254735573002 \#$ !tabs-1254736195353>.

IVARSFlaten, Elisabeth (2008). «What Unites the Populist Right in Western Europe? Reexamining grievance mobilization models in seven successful cases». Comparative Political Studies, 41 (1), 3-23. <https://doi.org/10.1177/001041 4006294168>

LEONISIO, Rafael (2013). "Las víctimas del terrorismo en el discurso de los partidos políticos vascos: una aproximación cuantitativa (1980-2011)». Revista de Estudios Políticos (Nueva Época), 161, 13-40.

- (2016). Cambio y continuidad en el discurso político. El caso del Partido Socialista de Euskadi (1977-2011). Madrid: CIS.

Llera, Francisco J.; LeOnisio, Rafael y PÉreZ, Sergio (2017). "The influence of the elites' discourse in political attitudes: Evidence from the Basque Country». National Identities, 19 (4), 367-393. <https://doi.org/10.1080/14608944.2016.1177006>

LYNCH, Gabrielle (2015). «Ethnic Politics». En: STONE, John et al. (eds). The Wiley Blackwell Encyclopedia of Race, Ethnicity, and Nationalism. Nueva Jersey: Wiley.

MENDES, Mariana y DENNISON, James (2020). «Explaining the emergence of the radical right in Spain and Portugal: salience, stigma and supply». West European Politics, 44 (4), 752-775. <https://doi.org/10.1080/01402382.2020.1777504>

Ministerio DEL INTERIOR (2019). «Resultados electorales». Recuperado de <http:// www.infoelectoral.mir.es/infoelectoral $/ \mathrm{min} />$.

Mudde, Cas (2000). The ideology of the extreme right. Manchester: Manchester University Press.

- (2007). Populist radical right parties in Europe. Cambridge: Cambridge University Press.

- (2019). The Far Right Today. Cambridge: Polity Press.

NederveEN, Jan (1996). "Varieties of Ethnic Politics and Ethnicity Discourse». En: Wilmsen, Edwin N. y McAllister, Patrick (eds.). The Politics of Difference. Chicago y Londres: University of Chicago Press.

NORRIS, Pippa (2009). Derecha radical: votantes y partidos politicos en el mercado electoral. Madrid: Akal. 
NTN24 (2019). Jaime Bayly Show. Recuperado de <https://www.youtube.com/ watch?v=7dDHOFv_KMY>.

- (2020). "Entrevista a Santiago Abascal, presidente de Vox». Recuperado de <https://www.youtube.com/watch?v=hu6sv-lY1cQ>.

Olmos, Antonia (2007). «La inmigración extranjera en el discurso político de Andalucía: un análisis del debate parlamentario». En: ZAPATA-BARRERO, Ricard y DiJK, Teun A. van (eds.). Discursos sobre la inmigración en España. Los medios de comunicación, los parlamentos y las administraciones. Barcelona: CIDOB.

Pennings, Paul y Keman, Hans (2002). "Towards a New Methodology of Estimating Party Policy Positions». Quality \& Quantity, 36 (1), 55-72.

<https://doi.org/10.1023/A:1014380123135>

RovNY, Jan (2013). «Where do radical right parties stand? Position blurring in multidimensional competition». European Political Science Review, 5 (1), 1-26. $<$ https://doi.org/10.1017/s1755773911000282>

Rubio, Vicente (2019). «Vox ¿Una nueva extrema derecha en España? Rosa Luxemburg Stiftung». Recuperado de <http://www.rosalux-nyc.org/wp-content/files_mf/ rubiovox_esp_final_web.pdf>.

SAYAGO, Sebastián (2014). «El análisis de discurso como técnica de investigación cualitativa y cuantitativa en ciencias sociales». Cinta Moebio, 49. <https://doi.org/10.4067/s0717-554x2014000100001>

SENADO (2020a). «Actividad parlamentaria del senador Jacobo González-Robatto Perote». Recuperado de <https://www.senado.es/web/composicionorganizacion/senadores/composicionsenado/fichasenador/index.html? id1 =19225\&legis=14\&id2=i>.

- (2020b). «Actividad parlamentaria del senador José Manuel Marín Gascón». Recuperado de <https:/www.senado.es/web/composicionorganizacion/senadores/composicionsenado/fichasenador/index.html? id1=19105\&legis=14\&id2=i>.

SteEnbergen, Marco R. y SCOTt, David, J. (2004). "Contesting Europe? The salience of European integration as a party issue». En: MARKS, Gary y STEENBERGEN, Marco R. (eds). European Integration and Political Conflict. Cambridge: Cambridge University Press.

Turnbull-DugarTe, Stuart. J. (2019). «Explaining the end of Spanish exceptionalism and electoral support for Vox». Research \& Politics, 1-8. <https://doi.org/10.1177\%2F2053168019851680>

Turnbull-Dugarte, Stuart J.; Rama, José y Santana, Andrés (2020). "The Baskerville's dog suddenly started barking: voting for VOX in the 2019 Spanish general elections». Political Research Exchange, 2, 1-21. <https://doi.org/10.1080/2474736x.2020.1781543>

Vox (2018a). «Acto de Vox en Vistalegre España Viva - 7 de octubre de 2018». Recuperado de <https://www.youtube.com/watch?v=E86yhLllmRk>.

- (2018b). «100 medidas para la España Viva».

- (2019). «Acto de Vox en Vistalegre Plus Ultra - 6 de octubre de 2019». Recuperado de <https://www.youtube.com/watch?v=8B_iAyQ5GAU>.

- (2020). «Acto de Vox en Vistalegre La Alternativa - 8 de marzo de 2020». Recuperado de <https://www.youtube.com/watch?v=4jKQ7vtfETQ>.

ZAPATA-BARRERO, Ricard (2007). «Política del discurso sobre inmigración en España». Discurso y Sociedad, 1 (2), 317-369. 
